\title{
Esclavitud o independencia: disyuntiva del liberalismo criollo oriental de la isla de Cuba en 1836
}

Olga Portuondo Zúñiga

UNIVERSIDAD DE ORIENTE

$\mathbf{E}$ I advenimiento del siglo XIX significó un cambio rotundo en las relaciones entre la metrópoli hispana y sus colonias de América. Más exactamente, desde la ocupación francesa de la península en 1808 , se cumplirían los pronósticos de los políticos avezados del despotismo ilustrado: ante la negativa de la corona a aplicar una política acorde con las necesidades sociales y económicas, comenzaba el desgajamiento de sus provincias ultramarinas. América continental tomó el camino de la independencia, en tanto Cuba y Puerto Rico siguieron atadas a España, y sus destinos quedaron comprometidos con el creciente ascenso de la burguesía liberal en el escenario del poder político español y esforzán- dose por transformar el panorama económico interno del país.

Por consiguiente, podría considerarse que la pujante burguesía criolla de la isla de Cuba se insertaría con beneplácito en los propósitos de desarrollo de la burguesía hispana. Nada más lejos de la verdad, los grandes propietarios de plantaciones (azucareras, cafetaleras o algodoneras) se habian visto ampliamente apoyados en sus ambiciones capitalistas de acceder a los mercados europeo y norteamericano por numerosas reales cédulas de Fernando VII. Éste hizo descansar en las finanzas de la oligarquía criolla los recursos para afirmar. se en el trono borbónico y para las acciones punitivas con las que pre- 
tendía rescatar su imperio en el continente americano.

En cambio, los periodos constitucionales (1812-1814 y 1820-1823) resultaron defraudantes para la burguesía criolla. Ella respetó las fórmulas constitucionales que apenas si operaron transformaciones en las funciones de los Ayuntamientos y diputaciones provinciales. Sus miembros procedían de idéntica elite social que la de los cabildos monárquicos. Es cierto que hubo alguna que otra conspiración de carácter independentista en muchas partes de la isla, pero todas inconexas, inspiradas en las fórmulas secretas de la masonería y pretendiendo la liberación con las intervenciones foráneas. La de los Rayos y Soles de Bolívar contaba con el libertador, y la del Águila Negra con los ejércitos mexicanos; porque la burguesía criolla nunca bus. có en serio la independencia política; por el contrario, anhelaba una mayor libertad económica para seguir explotando al negro esclavo en las plantaciones de productos tropicales y con ellos concurrir al mercado internacional. Es éste el origen de la gran desilusión del ex diputado a Cortes y presbítero Félix Varela en 1826.

Eso sí, tampoco podemos catalogar las etapas constitucionales como absolutamente negativas para el decursar político posterior de la isla de Cuba porque la libertad de prensa, aun con sus limitaciones, propició la discusión teórica de los principios de igualdad, libertad y fraternidad en múltiples publicaciones, y el Estado ponía mayor atención a la instrucción de las nuevas generaciones con métodos más racionales y pragmáticos, menos escolásticos.
Desde 1834 la capitanía general de la isla de Cuba quedó en manos de un militar de los derrotados en el conti. nente, el general Miguel Tacón y Rosique. Tempranamente se indispuso con la oligarquía habanera, a la que alejó del palacio de gobierno luego de decretar el ostracismo del líder de la juventud partidaria de la unión con España José Antonio Saco. También se agriaron sus relaciones con el intendente de Hacienda Claudio Martínez Pinillo, conde de Villanueva, por sus simpatías hacia los reyes del azúcar Aldama-Alfonso y compañía.

En 1833 moría Fernando VII y María Cristina se hacía cargo de la regencia de su hija Isabel II para continuar inclinando la balanza del poder a favor de los liberales, con tal de defender el derecho de su descendencia al trono ante el pretendiente don Carlos. La Constitución de 1812 y la guerra civil habían radicalizado conciencias en España, y el ejército se hallaba pletórico de hombres con deseos de materializar los principios de la revolución francesa. En agosto de 1836 se produjo el motín de La Granja, que proclamó una vez más en la metrópoli el restablecimiento de la trajinada Constitución.

En Cuba y Puerto Rico se abrió la nueva época constitucional, pero esta vez la burguesía liberal española estaba decidida a hacer valer las diferencias entre la metrópoli y sus colonias para dinamitar los sueños pro-España de la burguesía liberal de la gran isla antillana entre 1836 y 1837 . Que. daría en situación precaria la ilusión de ser provincia ultramarina de España, que siempre había sido el fundamento de la plataforma política y res. 
guardo social y económico del liberalismo criollo.

Santiago de Cuba fue el escenario primordial de los acontecimientos que se desencadenaron en la isla de Cuba en 1836. Era la capital de la jurisdicción de Cuba y del departamento Oriental desde que en 1607 quedara constituido; sujeto en materia de gobierno y guerra a la capitanía general, disfrutaba de autonomía en la administración del resto de las jurisdicciones que lo formaban: Baracoa, Bayamo y Holguín. Al oeste limitaba con la jurisdicción de Puerto Príncipe, bajo la eje. cutoria de Tacón.

Desde 1835 gobernaba el departamento Oriental el mariscal de campo Manuel Lorenzo, quien había peleado por España en el continente americano durante los años veinte del siglo XIX; pero era un partidario declarado del liberalismo, que combatió contra el carlismo a favor de Isabel II. Distanciado de los expoliadores intereses de la bur. guesía española, podía definirse como un romántico continuador de aquella corriente de la Ilustración del siglo XVII que estimaba prudente dar trato de provincia a las regiones ultramarinas del imperio.

Luego de asumir el mando del departamento Oriental, Lorenzo se en. frentó casi de inmediato con el capitán general; había visto disminuidas sus atribuciones al retirársele la facultad de nombrar tenientes de gobernadores políticos y militares en los pueblos de Jiguani, Manzanillo y las ciudades de Holguín y Baracoa, y por tener que sujetarse a la arbitraria censura de prensa impuesta por Tacón. Tiempo después expresaría cómo chocaba a sus principios el trato distinto que se le daba a la isla si se comparaba con la política vigente en España:

Pero la isla de Cuba era el reverso de la medalla. Nada de ayuntamientos electi. vos, nada de diputaciones de provincia, nada de garantías, nada de gobierno racional y regulado. Las leyes eran la voluntad absoluta, omnímoda, ilimitada del capitán general; y éste podía decir como Luis XIV: el Estado soy yo. ${ }^{1}$

Tacón también era liberal, pero respondía de una manera más realista a las aspiraciones de la burguesía sobre las colonias que aún le quedaban a España en América. El asunto era extraerles las riquezas antes de que se perdieran. Opinaba que los criollos llevaban en la masa de la sangre el odio a España, con independencia de su posición económica. Éste es el motivo por el que el capitán general acogió con disgusto el nombramiento de Lorenzo como gobernador del departamento Oriental, sabedor de su manera de pensar. Y éste no lo defraudó, pues desde su llegada se rodeó de los grandes hacendados de la jurisdicción de Cuba, reformistas pro-España identificados con las ideas de José Antonio Saco, para departir con ellos en los salones de la Filarmónica de Santiago de Cuba. Se congraciaba con la oligarquía local y enfurecía a Tacón al prestar su influencia para elegir a Saco como diputado a Cortes por el departamento Oriental. Así lo señala el notable educador habanero José de la Luz y Caballero, quien lo calificara como "nuestro Lorenzo". ${ }^{2}$ En respues-

\footnotetext{
1 Lorenzo, Manifiesto, 1837.

2 Fernández de Castro, Medio, 1923.
} 
ta, Tacón reclamó a la metrópoli su remoción. ${ }^{3}$

Lorenzo pensaba que la reina gobernadora respaldaría su actitud antitaconiana y aceptaría a Cuba como provin. cia ultramarina de España si esta actitud iba acompañada de una devota fidelidad a ella, Isabel II, ahora que el carlismo hacía dudar de su derecho al trono español. En este empeño pondría toda su nombradía militar, para llevar las cosas hasta las últimas consecuencias. Calculaba que los propietarios orientales apoyarían su postura secesionista a despecho de sus intereses materiales, y que le brindarian su respaldo en la dirección de la desobediencia a la despótica aplicación de las facultades omnímodas.

Durante las primeras décadas del siglo XIX, la jurisdicción de Cuba había alcanzado la estabilidad dentro del régimen de plantación, a causa del constante crecimiento de la población esclava por el frecuente ingreso de negros bozales. En el segundo cuarto del siglo XIX, la producción agrícola para el mercado estaba en pleno apogeo. No es coincidencia que, de los 42 partidos que tenía la jurisdicción de Cuba en 1841 , se concentrara la mayor fuerza de trabajo esclava en aquellos donde florecían ingenios, cafetales y algodonales (véase cuadro 1).

A lo largo de la primera mitad del siglo XIX, la población esclava superaría en la jurisdicción de Cuba el $50 \%$ respecto al total de población (véase cuadro 2).

3 Lorenzo, Manifiesto, 1837, p. 8; Archivo Nacional de Cuba (ANC), Reales Cédulas y Ordenes, leg. 102, núm. 26.
Pero estas cifras no sólo inducen a pensar lo descaminado que estaba en sus suposiciones Manuel Lorenzo, sino que constituyen buena parte de las razones que explicarán las vacilaciones de la burguesía criolla santiagueña en 1836. Es imprescindible destacar el total de la población de color, pues al añadir los libres de color se demuestra su peso total en el porcentaje respecto a la blanca (véase cuadro 3 ).

Una breve ojeada sobre el resto de las jurisdicciones del departamento Oriental revela que la jurisdicción de Bayamo no llegó a desarrollar la producción de mercancía con mano de obra esclava como en la de Cuba. En 1830 , el número total de esclavos en ingenios apenas superaba los $8000, y$ en cafetales sólo había poco más de 100. Conservaba su economía predominantemente ganadera y contaba con una alta proporción de libres de color en sus campos y en los centros urbanos de Bayamo, Manzanillo y Tunas, para un total de 15500 libres de color.

La jurisdicción de Holguín apenas incursionaba en la producción azucarera en zonas aledañas al puerto de Gibara. Cumplía papel de retaguardia de los que producían para el mercado exterior en el departamento Oriental, al suministrar alimentos y ganado de tracción para las plantaciones. Tenía una reducida población esclava ( $17.71 \%$ ) y de libres de color (11.25\%); por el contrario, existía una elevada población blanca $(71.02 \%)$ que realizaba las labores del campo.

La jurisdicción de Baracoa perpetuaba su retraso económico y escasa población, de modo que nada influ- 
Cuadro 1. Partidos de la jurisdicción de Cuba con mayor número de esclavos $(1841)^{\mathrm{a}}$

\begin{tabular}{|c|c|c|c|c|}
\hline Partidos & Núm. de esclavos & Cafetales & Ingenios & Algodonales \\
\hline Sabanilla & 844 & 9 & 6 & \\
\hline Maroto & 971 & 5 & 4 & \\
\hline Enramada & 1115 & 24 & 11 & \\
\hline Palma Soriano & 900 & 10 & 6 & \\
\hline Morón & 845 & 9 & 13 & \\
\hline Hongolosongo & 1622 & 78 & 15 & \\
\hline A mistad & 1470 & 35 & & \\
\hline \multicolumn{5}{|l|}{ Armonía de } \\
\hline Limones & 1014 & 24 & & \\
\hline Guaninicum & 1896 & 43 & & \\
\hline Ti Arriba & 935 & 70 & 2 & \\
\hline \multicolumn{5}{|l|}{ Paz de los } \\
\hline Naranjos & 1235 & 13 & & \\
\hline San Andrés & 969 & 17 & 6 & \\
\hline Santa Catalina & 1818 & 15 & 4 & 48 \\
\hline
\end{tabular}

Cuadro 2. Porcentaje de población esclava en la jurisdicción de Cuba entre $1820 \cdot 1855^{\mathrm{b}}$

$\begin{array}{cccc}\text { Años } & \text { Porcentaje } & \text { Años } & \text { Porcentaje } \\ 1820 & 49.53 & 1841 & 53.43 \\ 1828 & 53.93 & 1846 & 55.35 \\ 1830 & 54.68 & 1855 & 40.05\end{array}$

Cuadro 3. Relación porcentual de blancos y de color en la jurisdicción de Cuba ${ }^{\mathrm{b}}$

Años

1820

1828

1830

1841

1846

1855
Blancos \%

22.44

22.22

21.64

21.49

25.33

24.83
Total de color $\%$

77.75

77.76

78.35

78.50

74.66

75.07

atos de fines de 1841 en Resumen, 1860.

b ANC, Gobierno General, leg. 392, núm. 18 634; Cuadro, 1829; Memorta, t. Ix, 1839; Resumen, 1842, pp. 50-51; Cuadro, 1847; García de Arboleya, Manual, 1859; Erenchun, Anales, 1858. 
yó en los acontecimientos que se desencadenarían en 1836.

Para la burguesía oriental, depen. diente del mercado de "piezas de in. dia", la situación internacional ofrecía un alto grado de desconfianza y tensión. Enfrascada en el fomento del capitalismo industrial, Gran Bretaña decretó la abolición de la esclavitud en 1833 en sus colonias, e hizo firmar a España un nuevo compromiso de suspensión de la trata. Ningún hacendado criollo era ajeno a los rejuegos políticos entre Inglaterra y Estados Unidos, ya que ambos pretendían adquirir por compra la isla, no por nada Estados Unidos había dictado su doctrina Monroe.

Todavía se escuchaban en Hispanoamérica los ecos de recientes combates por la emancipación. La proximidad de la República de Haití infundía pavor, mientras que los corifeos taconianos ayudaban a las elucubraciones de los propietarios orientales sobre terribles planes de desembarco en el que los jefes de la vecina república negra respaldarian a algunos generales de la recién concluida independencia sudamericana-Mariño por ejemplo-, para alzar a miles de esclavos contra sus amos en el departamento Oriental.

La vertiginosa carrera del capitalismo mundial provocó la inversión de ingleses, franceses, norteamericanos, etc. en todas las jurisdicciones del departamento Oriental, con preferencia en la jurisdicción de Cuba, ya en forma individual ya de compañías, en su agricultura, industria y comercio.

Los trabajos de extracción de mineral se iniciaron en 1830 en los yaci- mientos de El Cobre. Dos de las compañías que allí se fundaron fueron de capital británico: la Compañía Consolidada y la Compañía de Santiago. Ambas emplearon máquinas de vapor y más de 900 esclavos, a pesar de que su país había abolido la esclavitud en sus colonias y perseguido la trata. El cón. sul británico, John Hardy Jr., que representaba a su padre como accionista principal de la Consolidada, era su administrador, con cientos de esclavos de su propiedad o alquilados. ${ }^{4}$

No es de extrañar pues, que por la situación estamental ya descrita, las autoridades santiagueñas tomaran sus prevenciones en la década del treinta del siglo XIX.

Como los cimarrones bajaban y ata. caban reiteradamente a las plantaciones, fue preciso en 1833 la intervención del gobernador José Santos de la Hera para, con tropas regulares y con la formación de partidas financiadas por los hacendados, combatirlos como en décadas anteriores. El problema del apalencamiento de los negros cimarrones y sus incursiones sobre las haciendas se reduciría, pero nunca quedaría exterminado. ${ }^{5}$

Durante la administración del gobernador Santos de la Hera, se desató en La Habana una epidemia de peste. Entre las medidas adoptadas en 1832 por la Junta de Sanidad dentro de la jurisdicción de Cuba, para impedir la difusión de la epidemia, estaba la de negar cualquier tipo de reunión entre

4 González Locertales, "Minería", 1980, pp. 256-257.

5 ANC, Asuntos Políticos, leg. 226, núm. 13 y leg. 117, núm. 53. 
los libres de color, ${ }^{6}$ según razón, porque eran ellos los más propensos por sus miserias a contraer la enfermedad. Aunque esto último era cierto, detrás de la disposición sanitaria se encontraba también el interés político de la oligarquía santiagueña de evitar posibles conciliábulos y conspiraciones entre la gente de color. Se recelaba de las negradas de las plantaciones, pero era mucho más el miedo a los mulatos y negros libres por su mayor prepara. ción y conciencia social, al igual que por su desempeño principal en la producción rural y urbana del departamento.

Algunos mulatos y negros libres habían llegado a amasar ciertas fortunas. En la villa de El Cobre, donde la concentración de gente de color era particularmente significativa, se restableció un medio Ayuntamiento, en octubre de 1832, con seis regidores negros y mulatos dueños de ingenios, cafetales $\mathrm{o}$ arrias de mulas. Esto provocó malestar entre los blancos. ${ }^{7}$

El 29 de septiembre de 1836 entraba en el puerto de Santiago de Cuba el bergantín mercante Guadalupe, cuyo patrón traía algunos ejemplares de la $\mathrm{Ga}$ ceta de Madrid con el Real Decreto del 13 de agosto en el que se proclamaba de nuevo la Constitución de Cádiz en España tras el pronunciamiento de La Granja. Traía tambiên noticias de que, en Puerto Rico, el capitán general, conde de Torrepando, había jurado ya dicha Constitución desde el 22 de septiembre. ${ }^{8}$

${ }^{6}$ Archivo Histórico del Poder Popular de Santiago de Cuba, Actas Capitulares, núm. 53, 1832.

${ }^{7}$ Representación, 1835.

8 Navarro García, Esclavos, 1991 , pp. 73-83.
Así es que el gobernador del departamento Oriental, Manuel Lorenzo, creyó el momento indicado para enfrentarse a Tacón y promover el federa. lismo luego de proclamada, de forma resuelta, la Constitución en el territorio de su administración:

Habitantes de la provincia de Cuba; yo he jurado en balde la Constitución [...]. Lo que han jurado mis labios, mi espada lo sostendrá; que no he derramado sangre en los campos ni consagrado mi vida a la patria para venir a mancharla en sus últimos periodos con criminales debilidades ni sacrílegos perjuicios. ${ }^{9}$

En los primeros momentos, los criollos blancos, dueños de plantaciones azucareras y cafetaleras, secundaron en buena mayoría a Lorenzo. Por ejemplo, José y Mariano Vaillant y de las Cuevas, Francisco Mozo de la Torre, Juan Kindelán, Francisco Antonio Garzón, Francisco Muñoz del Monte, José Rodríguez, Agustín de la Tijera, Antonio Bruno Vaillalón, Ignacio de Peralta, Marcelino de las Cuevas, Andrés Durán, etc., formaron el cabildo constitu. cional y la diputación provincial. ${ }^{10}$

El cabildo eclesiástico de la catedral

${ }^{9}$ Archivo de la Iglesia Catedral de Santiago de Cuba, Gobierno Militar y Político (1832-1856), caja núm. 15. Proclama de Manuel Lorenzo titulada "Cubanos", 20 de octubre de 1836.

10 José Vaillant y de las Cuevas era el marqués de la Candelaria de Yarayabo, prócer del reino, y había sido condecorado recientemente con la orden de Isabel la Católica. Como todos los mencionados, procedía del patriciado criollo surgido en el siglo XVII y fortalecido en el siglo XVn. Eran dueños de ingenios, cafetales, haciendas ganaderas y cientos de esclavos y constituían lo más rancio de la elite burguesa de la jurisdicción de Cuba. 


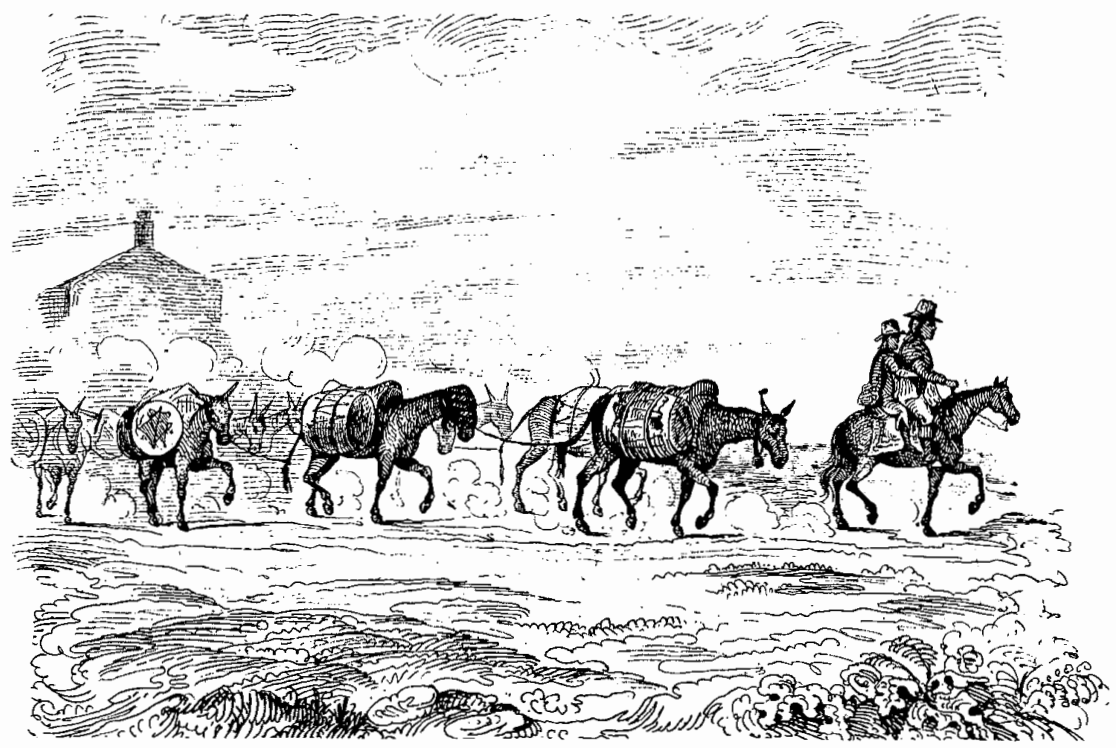

juró también la Constitución durante el acto de publicación de la misma en Santiago de Cuba el 1 de octubre. El dean Bartolomé Mascareña, el magistral Gabriel Marcelino Quiroga, el lectoral Hidalgo, los racioneros José Teodoro Martínez y Antonio Odoardo, los medios racioneros José Santos de León y Manuel Sánchez, y hasta el secretario Miguel A. Pérez, compartieron las muestras de júbilo popular de la ciudad, aunque el arzobispo no la aprobara. Muchos de ellos procedían de viejas familias patricias criollas.

Hacendados más cautos juraron la Constitución pero, al decir de la época, prefirieron "mirar los toros desde la barrera" sin comprometerse con un gobierno que la regente no había reconocido y Tacón se obstinaba en rechazar.
La mayoría de los comerciantes, de origen catalán, juraron hipócritamente la Constitución y comenzaron a socavar las bases del gobierno de Lorenzo, al igual que muchos de los funcionarios de la Real Hacienda, y oficiales del ejército y de la marina. El arzobispo carlista, fray Cirilo de Alameda y Brea, terminó por jurar la Constitución a regañadientes, mientras se iniciaba en labores conspirativas de la facción protaconiana.

Las tropas regulares integradas por los cuerpos de León y Cataluña mantenían sus opiniones dividas. Levantiscos y amenazadores de la vida política del departamento, respondían en última instancia a las decisiones de sus jefes. A ninguno de los propietarios criollos santiagueños los conminaba 
una acción política independentista; su radicalismo liberal no iba más lejos que el reformismo al estilo de Saco -quien entendía la nacionalidad como algo privativo de los blancos-, pero compartían la repulsa a Tacón por su despreciativa actitud hacia todos los cubanos, motivo que le había ganado los ataques de acaudalados habaneros como Domingo del Monte, primo de Francisco Muñoz del Monte, abogado y literato santiagueño; éste, junto con Juan Kindelăn y Juan Bautista Sagarra, hicieron las veces de ideólogos del ré. gimen de Lorenzo. ${ }^{11}$

$\mathrm{Ni}$ aun los más radicales entre los reformistas orientales estaban dispuestos a sacrificar los beneficios eco. nómicos por preservar Ia Constitución, ni llegar hasta las últimas consecuencias para respaldar la acción antitaconiana de Manuel Lorenzo, a reser. va de lo que éste pudiera pensar.

Sirvan de ilustración las palabras que, según varios testigos, pronunciara el destacado pedagogo y miembro de la burguesía santiagueña, Juan Bautista Sagarra. Entendia,

[...] que era un déspota el general Tacón, que la expedición que preparaba venía en la falsa creencia de que aquí se tramaban planes de independencia; que por ahora semejantes proyectos eran quiméricos e irrealizables; que él desea. ba la independencia tanto como el primero, y que por ella detramaria su últi-

11 Licenciado Francisco Muñoz del Monte, abogado, poeta y escritor; Juan Kindelán, diputado a Cortes y coronel del batallón de Milicias Nacionales; licenciado Juan Bautista Sagarra, notable pedagogo promotor de muevos métodos pragmáticos para la educación de las juventudes santiagueñas. ma gota de sangre, pero que conocía que esto era imposible porque el resultado de una lucha entre los blancos no sería otro que poner la isla en manos de la gente de color. 12

Como Sagarra, discípulo predilecto de Luz y Caballero, pensaban todos los hijos del país dueños de plantaciones.

Durante los primeros días del mes de octubre de 1836 se juraba la Constitución en el resto de las jurisdicciones y pueblos del departamento Oriental.

Enterado Tacón de las últimas noticias en el oriente de la isla, su respuesta fue decretar la incomunicación del departamento Oriental y el bloqueo al puerto de Santiago de Cuba, sabedor de que la reina había limitado los efectos de la acción constitucional sólo a la península e islas adyacentes.

El historiador cubano decimonónico, Manuel Villanova ${ }^{13}$, se refirió en magníficas palabras a la insurrección de Lorenzo para denotar la importancia que atribuía a los hechos y su profundo conocimiento de los mismos. Pero él pensaba que éste era el momento propicio para que el gobernador constitucionalista invadiera la vecina jurisdicción de Puerto Príncipe y facilitara la incorporación del centro de la isla a los designios secesionistas para que las autoridades políticas, militares e incluso los magistrados de la Real Audiencia, juraran la Carta Magna. Loren zo no podía hacer esto; en primer lugar, porque hubiera tenido que hacer

\footnotetext{
12 ANC, Comisión Militar Ejecutiva y Permanente: Expediente de Causa de Juan Bautista Sagarra.

13 Villanova, Economía, 1945.
} 
frente a la resistencia del teniente gobernador Antonio Vázquez, quien había recibido órdenes concretas de subordinación a la capitanía general, y el gobernador del departamento Oriental no disponía de base logística adecuada para llevar a cabo esta campaña; en segundo lugar, y por sobre todo, su respeto a la monarquía le impedía esta acción bélica, ya que una invasión a Puerto Príncipe significaba la desobediencia al orden administrativo estatuido por la corona en la isla. Es por eso que optó por hacerse fuerte en su gubernatura y dio órdenes de acelerar la reorganización de las milicias de blancos y mulatos que ya había iniciado el 6 de octubre; mientras tanto, enviaba una representación a la reina para que ésta diera su consentimiento a las medidas adoptadas.

Los propietariosde las plantaciones orientales no favorecieron el reclutamiento miliciano; no querían extraer a los hombres libres del cultivo de la tierra y temían armarlos. El diálogo publicado en Santiago de Cuba el 26 de octubre $^{14}$ resulta mucho más esclarecedor sobre este asunto que mis propias palabras. Se trata de una conversación entre un tal don Ildefonso de Trabacuentas y un guajiro, a quien le había arrendado tierras en su finca La Trampa. Seleccionamos estos párrafos:

Guajiro: Pro que como se ha aclarao la Contutución en la suidá, $y$ me icen que se están organizando melicias nuevas, osté y yo hemos de dirnos a meter a me. lecianos, y en esas cerconstancias quea-

${ }^{14}$ Diario Constitucional de Santiago de Cuba, 26 de octubre de 1836, p. 3. rá la icienda sin amo ni mayoral, al solo cuidiao de los taitas tiznaos.

Don Ildefonso: Eso de ningún modo. Conque yo me haya apuntado, aunque a pesar mío, en esa farándula militar, como lo he practicado, basta y sobra. Por lo que respeta a tí, no debes pensar en abandonarme la casa. Tu empaque, tus años, tu montaraz impericia, no son cualidades aparentes para un soldado nacional.

Guajiro: ¿Qué es lo que osté ice?, pues yo me inriputo que podería ser hasta tiniente. Mi rebustez, mi habelidá en jugar el garrote, $y$ an fin, el ser como somos suidadanos los que por la promisión de Dios lo somos, me paece a mi paecer que yo pueo ser tan meliciano como el Ci' campaor.

Don Ildefonso: ¿YY quién te ha metido en la cabeza tales ciudadanías?

Guajiro: Ellas se me han metío, ellas solas e por sí mesmar.

$[\ldots]$

En esto se marchó Silvestre del cortijo de don Ildefonso, y por el camino venía haciendo el soliloquio siguiente:

A bien que el feje polético es güeno y me jará justicia. Yo soy capaz de dirme jasta el Guayamo con la pata por el suelo, a recebir a esos que icen que vienen a jacernos el coco. En día y en volvía no echaré unos disocho menutos, $y$ en topándome con los anemigos, verán ellos quién es Cajellas. Por esto de la comía, no tengo el más nímino cudiao; con un pa e plátanos y un chicote e tasajo, como Lonisio, como flaire Geromo, y quea tan jarto como un bicerro. Pero, y ese vescaíno del dianche don Alifonso, se ha é quear con mi inero; No, no; le voy a incusar en el mimento que salga del espital, de la enjuria jecha a mi persona. Cuando esté yo a la princecia de si insistencia le contaré de pa pa toa esta tram- 
polina, y ansina consiguiente le juré ver, que como Lonisio, hay una pipinada de Lonisios allá en mi partío de la majagua, que están preparaos con sus jerrones y sus machetes, para incarmentar a cuantos embazores vengan de la uelta abajo. La cuistutución que hemos jurao se ha de mantener intauta, anque se imponga toitico el iniverso. Custutución o samenterio: Isabel Segunda y Crestina: lebertá o turrumoto. Viva la suidá de Cuba y muera toos los alversarios, juntamente con el burro del tío Pilicarpio que se comió el malojo de don Alifonso, y don Alifonso también. A.R.

El diálogo ejemplifica todo el temor de los hacendados a la población arma. da negra, libres o esclavos; a que ellos intentaran reivindicar por su cuenta sus derechos y necesidades sociales.

Al recibir Tacón nuevas órdenes que reiteraban el apoyo metropolitano a sus determinaciones contra el gobernador del departamento Oriental, hizo más firmes estas decisiones y ordenó a Lorenzo la entrega del mando al brigadier Juan de Moya y Morejón con el propósito de que éste restableciera el orden de cosas anterior al 29 de septiembre. Enterado de las órdenes, Lorenzo puso preso a Moya y el $10 \mathrm{de}$ noviembre envió a España a dos hom. bres de su entera confianza, su asesor personal Porfirio Valiente y su ayudante Benito Rubio Bocanegra con representaciones para la reina. ${ }^{15}$ Su postura implicaba su insubordinación al capitán general; para resistir, consideró el apoyo que podía darle la mayor parte de la población, y es por esto que, una vez más, convocó a la Milicia Nacional.

15 Villanova, Economía, 1945, p. 339.
Tacón reforzó el bloqueo a la bahía santiagueña y comenzó a preparar una expedición que por mar y tierra se dirigiría al departamento Oriental para imponer el orden por la fuerza. Tam. bién promovió la quinta columna en todo el territorio de la provincia y acusó de velado independentismo a los que apoyaban a Lorenzo, y a éste de secundar dichos planes.

Hábil, como siempre, el capitán ge. neral de la isla jugó con todas las cartas, incluyendo la fidelidad a la monarquía de Manuel Lorenzo y el conservadurismo antiindependentista de los criollos orientales.

La rapidez con que Lorenzo debía llevar a cabo la escalada contra Tacón se vio frenada por los temores e indecisiones de los hacendados orientales, en particular de las jurisdicciones de Cuba y de Bayamo. No era la primera vez que un levantamiento faccionalista de un general español en una provincia americana se convertía en terreno fértil para desembocar en movimiento independentista.

Los cónsules de Gran Bretaña, John Hardy; de Francia, Esteban David, y de Estados Unidos, Michael Mahon, comunicaron a Lorenzo su preocupación por el peligroso cauce que tomaban los acontecimientos para la propiedad y las vidas de sus compatriotas. Paralelamente, reclamaban a sus gobiernos medidas de protección para actuar si la situación se hacía más difícil.

El 25 de octubre, John Hardy Jr. informaba al comodoro de la base de Jamaica, sir John Peyton, que Lorenzo había procedido a organizar la Milicia Nacional con el objetivo de resistir cualquier intento de derrocamiento del nuevo siste- 
ma. Añadía que los grandes terratenientes no estimaban que el régimen constitucional se adaptara a un país en el que existía la esclavitud y las diferencias estamentales. Opinaba que la región quedaría sometida de nuevo al viejo orden de cosas. Hardy decía que

[...] la revolución de la América española ha comenzado por conf lictos regionales entre los jefes designados por España, y en caso de una crisis mayor ésta sería aprovechada por las clases excluidas y por los soldados desafectos para entrar en ebullición; someto a su considera. ción si no debería valorar el peligro y despachar un barco de guerra a este puerto para protección de los intereses británicos $[\ldots]^{16}$

El comodoro Peyton respondió con el envío del capitán William Jones en la fragata inglesa Vestal, estacionada en Jamaica. Jones se acercó a Lorenzo y se brindó para lograr de un entendimiento con Tacón. Sus gestiones fueron infructuosas. ${ }^{17}$ Mientras, la vivienda del cónsul Hardy se convertía en el mayor centro conspirativo de la ciudad santiagueña. A mediados de noviembre, el capitán de la Vestal llegó a La Habana. En conciliábulos del capitán general con algunos cónsules, se acordó que Jones debía intervenir como mediador, proponiéndole a Lorenzo la renuncia a cambio del respeto a su integridad personal y la de sus más cercanos colaboradores. De regreso en Santiago se tropezó con una nueva negati-

16 Library of Congress, Domingo del Monte Collections. 1836-1837, núm. 1, núm. 36.

17 Portell Vilá, Historia, 1938, pp. 308-309.

18 Ibid. va del gobernador del departamento Oriental. ${ }^{18}$ Entonces cooperó con Hardy propalando el temor a la irremisible devastación que provocaría el in. minente choque de las fuerzas en pugna, y se dedicó a ganar adeptos para las filas de los conservadores tradicionalistas.

El propio Jones, al escribir sobre su gestión en Cuba a fines de 1836 al co. mandante en jefe de la base de Jamaica, vicealmirante sir Peter Halkett, enumera la serie de intereses británicos puestos sobre el tapete en el momento del conflicto: ${ }^{19}$ a) La pérdida del comercio entre Kingston y la isla de Cuba o de todo el comercio británico con la Gran Antilla; $b$ ) la destrucción de las valiosas instalaciones en las minas de cobre recién abiertas cerca de Santiago, para lo que se empleaban miles de toneladas en barcos británicos, donde se enviaba el mineral hacia Inglaterra; c) que se hiciera necesario incrementar la fuerza naval británica en aquella zona del Caribe para cuidarse de la piratería que provocaría la guerra civil; $d)$ por las mismas razones, la probable necesidad de aumento de tropas en Jamaica, para lo que tendría que prescindirse de la Guardia Negra en caso de desencadenarse un conflicto racial inmediato a sus costas y tan re. ciente de la liberación de sus esclavos, y e) no por último menos importante, creaba el pretexto para que otros poderes intervinieran, muy particularmente Estados Unidos, cuyo gobierno no tenía puntos de vista coincidentes con la política británica en cuanto al

19 Library of Congress, Domingo del Monte Collections. 1836-1837. 
Caribe y el resto de la A mérica hispana.

El cónsul francés intervino para que se cuidaran las propiedades agrarias y los intereses comerciales de sus súbditos. Por ejemplo, los franceses Casamayor y Nuiry, cafetaleros y comerciantes al por mayor, fueron siempre desafec. tos al constitucionalismo.

También existían casas comercia. les, ingenios y cafetales en manos de ciudadanos norteamericanos en la jurisdicción de Cuba, pero la preocupación mayor de Estados Unidos era la puesta en peligro del comercio clandestino de negros bozales, que sus tratantes realizaban en el país.

La conspiración anticonstitucionalista anidó en oficiales tan cercanos a Lorenzo como el jefe de uno de los regimientos de la ciudad, Pedro Becerra, y en el comandante de marina José Ruiz de Apodaca. Por su parte, el intendente de Hacienda, Luis de Alda, se dedicaba a boicotear cualquier tipo de ingreso al fisco, por eso propició la negativa de los propietarios a pagar los arbitrios relativos a esclavos y pulperías y puso trabas al financiamiento de las milicias y las defensas en general. En el mes de noviembre, el cónsul Hardy dirigía a Lorenzo un informe de rechazo a la decisión de la Diputación Provincial, inconsecuente según él, sobre el cobro de impuestos por derechos de exportación del mineral de cobre, puesto que iba en contra del derecho minero español vigente.

Para oponerse a la expedición pacificadora, Lorenzo mantuvo una posición intransigente. Ordenó reclutar un número mayor de hombres libres en edad de tomar las armas, fueran blan. cos o negros. Los taconianos asegura- ban que había llegado a manifestar que echaría de vanguardia 800 negros que habían prometido algunos hacendados. La expresión es consecuente con su postura, nunca con la realidad del momento.

Sabía que debía hacer una guerra con tropa del pueblo en busca del desgaste enemigo a través de una larga resistencia. Es natural que esta estrategia defensiva no fuera acogida con beneplácito por la burguesía oriental. En la práctica, para ellos significaba: a) ausencia de la mano de obra libre en el campo y su distracción de las ocupaciones cotidianas al dedicarse al entrenamiento y la defensa; $b$ ) dejar las plan. taciones indefensas ante sus negradas esclavas y la amenaza perenne de los cimarrones de las montañas; c) los libres de color ganaban en conciencia política y autoridad para defenderse de la explotación y de los frecuentes abusos a que eran sometidos, y d) con las armas en la mano serían capaces de exigir sus derechos por la fuerza.

El 29 de noviembre de 1836, Manuel Lorenzo hacía circular un impreso que convocaba a la formación de las milicias en tẻrminos drásticos:

El día 8 del entrante diciembre se hallará usted indefectiblemente en esta plaza con todos los individuos licenciados del batallón de infantería provisional que se encuentren en ese partido, lo mismo que con los que pertenezcan a los Cuerpos de Milicias blancas y pardas de esta ciudad y villa de Bayamo, y también con todos los pardos solteros desde la edad de diez y ocho a treinta y seis años, residentes en ese propio partido; bien entendido que si por alguna causa legítima no pudiese usted verificar esta impor- 
tante operación que tanto interesa al servicio nacional, podrá en tal caso encargar de ella a uno de sus tenientes, o a cualquiera otra persona blanca de su confianza. Este gobierno no duda que usted con su bien conocida eficacia, sabrá llenar debidamente este encargo, haciendo que se formen relaciones nominales de todos los individuos expresa. dos, las cuales me serán entregadas por usted o por la persona comisionada para conducirlos a esta plaza en el día señalado, en el concepto de que pesará sobre usted la más grave responsabilidad en el evento de que, por cualquier motivo, no se efectuase puntualmente esta orden de cuyo recibo me dará aviso anticipado para mi gobierno. 20

Lorenzo dirigió la orden a los capitanes de partido con la intención de resistir valientemente; una vez más los hacendados se negaron a concurrir con sus subordinados libres. iQué podía esperarse de ellos, cuando ni el al. calde primero constitucional, Francisco Mozo de la Torre, la obedecía!

A mediados de noviembre salía de La Habana y avanzaba por tierra un escuadrón de lanceros del rey, pues la expedición pacificadora no saldría desde Batabanó sino hasta después de enero 3 de $1837 . .^{21}$ El éxito que procuraba el capitán general se hallaba en sembrar la duda, la inseguridad y el temor a la destrucción de las propiedades entre las filas de los constitucionalistas. En tanto, Lorenzo pretendía la fidelidad de sus partidarios dándoles

${ }^{20}$ ANC, Correspondencia de los Capitanes Generakes.

21 Navarro García, Esclavos, 1991, pp. $115-120$. garantías de no armar a los esclavos pero todo era inútil.

Dispuesta a salir la expedición bajo el mando del comandante general Joa. quín Gascué, el 17 de diciembre el Ayuntamiento santiagueño acordó formar una comisión que justificaría su proceder ante Tacón y que buscaría garantías para sus negocios. Esto era la claudicación.

Mientras hacendados y comerciantes se las ingeniaban para salir airosos de la coyuntura, ${ }^{22}$ la situación en la capital departamental se hacía más tensa entre el 17 y el 23 de diciembre. Las capas bajas de la sociedad santiagueña, muchos soldados y sargentos del cuerpo de Cataluña, reclamaron a Lorenzo la adopción de medidas más radicales para defender la Constitución, en tanto lo dejaban solo los hacendados crio$110 .^{23}$

Los comisionados burgueses redactaban sus peticiones el 19 de diciem. bre para llevarlas al capitán general. ${ }^{24}$ Algunos puntos les eran objetados, pues no podría mantenerse ni el Ayuntamiento constitucional, ni la Milicia Nacional, ni la Diputación Provincial como pretendian; no así su solicitud de respeto a las personas y propiedades, ya que el propio Tacón quería impedir los cambios demasiado bruscos que pudieran provocar el estallido de una sublevación entre los ilusionados criollos blancos de bajos estratos y los libres de color.

Mientras los detractores de Lorenzo

22 Bacardí y Moreau, Cárdenas, 1908, t. II, pp. $489-490$.

23 Ibid., t. I, pp. 497.500

24 Ibid, t. n, pp. 498-499. 
se reunían para discutir los términos de la capitulación de Santiago de Cuba, durante la madrugada de ese mismo día los comerciantes catalanes y los oficiales de la guarnición de Bayamo daban un golpe de Estado al gobierno constitucional de la villa. ${ }^{25}$

Se había desatado el rumor de que los libres de color se insurbordinarían en Yara junto con los esclavos de aquella zona y de Manzanillo -ambas en la jurisdicción de Bayamo- aprovechando que se había ordenado el traslado de las cajas de la Real Hacienda, de la caballería y tropas de Manzanillo, y que quedaria desguarnecido el territorio. La orden había sido dictada por Ma. nuel Lorenzo, que disponía la concentración de tropas en Jiguaní con la finalidad de establecer allí la defensa principal contra la expedición pacificado. ra. El pánico al alzamiento de los negros fue causa inmediata para el derrocamiento del gobierno constitucional en Bayamo.

A hora, los propietarios orientales preferirían confiar sus esperanzas -como los propietarios habaneros- en la apertura de las Cortes españolas. Los criollos orientales se adhirieron al criterio de que el desprecio de Tacón era un problema de personalidad despótica y se ilusionaron con el cambio que sobrevendría luego que sus diputados hicieran valer sus derechos de equidad como provincia española. Mucho se engañaban los reformistas respecto a las intenciones de Madrid.

Los acontecimientos de Santiago y Bayamo ofrecían un cariz cada vez más desfavorable para el gobernador orien-

25 Lorenzo, Manifiesto, 1837, p. 17. tal, y éste decidió también esperar la apertura de las Cortes, pues no recibía el respaldo de la regente, Isabel II. Convocó a junta militar y entregó el mando a un individuo de la mediación, Santiago Fortún. Siempre dispuesto, Jones condujo esa misma noche del 23 de diciembre a Manuel Lorenzo y sus más cercanos colaboradores hasta la Vestal.

En las cercanías del puerto se hallaban apostados tras barricadas los comerciantes catalanes, reforzados con la marinería de los barcos bloqueadores. Milicianos nacionales y el segundo regimiento de ligeros de Cataluña gritaban consignas radicales a favor de la Constitución. Se creó un estado de efervescencia revolucionaria que parecía a punto de estallar en el pueblo y los soldados, pero los liberales progresistas se desmoralizaron al abandonar Lorenzo la lucha y por la intervención de algunos oficiales - hasta entonces del constitucionalismo-, que aplaca. ron los ánimos, temerosos de un desbordamiento que condujera a una insurrección armada fuera de su control.

La respuesta de por qué fracasó la acción de Lorenzo hay que buscarla en la timorata actitud de la burguesía criolla oriental, demasiado comprometida por sus ataduras económicas y sociales. De ahí se deriva su dependencia de los criterios que emanaban de la monarquía constitucional, su falta de unión en torno a la figura del gobernador departamental, y su delegación de responsabilidades defensivas en los ejércitos regulares, que la llevaba a rechazar la formación de milicias nacionales integradas por blancos, negros $y$ mulatos.

Hay que decir, en contra de Loren- 
zo, que no hizo concesiones reivindicativas a los negros libres y esclavos en el terreno social y, por ende, éstos no se sintieron obligados a secundarlo. Su renuncia al mando significa que persistió en no menoscabar la autoridad de la monarquía española en la isla; pero no podemos atribuirle la principal responsabilidad del fracaso de la insubordinación, ya que siempre prohijó la tendencia más radical. La responsabilidad mayor es de los propietarios criollos orientales, quienes volvieron sobre sus pasos y se negaron a continuar la escalada revolucionaria que bien podía conducir, como pensaba acertadamente Tacón, al camino de la lucha independentista.

La zafra acababa de iniciarse y los precios en el mercado mundial eran favorables; mejores aún los del café y el algodón. No eran buenas razones para arriesgar cosechas y paralizar la producción industrial de continuar el bloqueo impuesto por la capitanía general. Éste era el pensamiento principal de los propietarios orientales y de los extranjeros radicados en el país. Así pensaba Hardy Jr., quien no podía ver con buenos ojos que sus beneficios en las minas de El Cobre, sin pagar apenas impuestos, se fueran a volar, ni arriesgar sus inversiones en máquinas de vapor y esclavos tan solo por la obstinación del gobernador del departamento Oriental.

La situación creada durante los 83 días comprendidos entre el 29 de septiembre y el 23 de diciembre de 1836 en el departamento Oriental, puede ser definida como de insubordinación encabezada por un iluso liberal espanol confundido en su papel de defen- sor de los intereses imperiales en las colonias que aún permanecían bajo do. minio de España. Secundado al principio por los liberales burgueses orientales (reformistas-pro-España), fueron ellos incapaces de dar participación al pueblo en la defensa de las conquistas constitucionales del departamento Oriental. A los sentimientos nacionales sobreponían su condición social, limitando la libertad a puras expresiones abstractas. Y no podía ser de otra manera cuando en la región florecía la producción de mercancías con mano de obra esclava. En el creciente ascenso revolucionario repercutió desfavorablemente la desconfianza de los blancos a la intervención de la gente de color, ni siquiera de los libres, porque los propietarios blancos burgueses creían que el negro no constituía un elemento de integración de la nacionalidad cubana, ni estimaban tampoco que el progreso de la isla podía hacerse fuera de la nación española, ya estuvieran en el poder monárquicos o liberales.

Cuando las fuerzas expedicionarias encabezadas por el general Gascué lle. garon por Manzanillo al departamento Oriental, su única misión sería reafirmar el orden de cosas deseado por Tacón. Atacado por la burguesía criolla habanera, indispuesto con el intendente Martínez Pinillo y por la tensa situación entre la población oriental, Tacón decidió no tomar medidas demasiado represivas considerando su precaria situación política en la capital colonial. Algunos fueron condenados a años de cárcel; una buena parte a la deportación. El retorno de los más comprometidos se produciría en 1841 , luego de una amnistía general. 
El fracaso de la asonada antitaconiana quedaría íntimamente relacionado con la exclusión de los diputados de la isla de Cuba a las Cortes españolas en febrero de 1837. La decisión de crear leyes especiales para los territorios de ultramar llevó a muchos a la comprensión de la amarga verdad. La isla de Cuba era una colonia de España.

En la Asamblea Constituyente que se reunió en Madrid se hallaban los más caros representantes del liberalismo español, quienes evidenciaron con sus discursos que las medidas represivas de Tacón y su oposición al constitucionalismo de Lorenzo no eran simples decisiones arbitrarias del déspota, sino toda una política colonial del liberalismo burgués peninsular con intereses bien distintos a los de los liberales criollos burgueses de la isla de Cuba. Para éstos, la decisión de las Cortes españolas era una bofetada en pleno rostro y la puesta en una situación precaria de su programa político, el fracaso del integracionismo-reformista criollo.

Entre septiembre y diciembre de 1836 , las capas bajas criollas de todo el departamento Oriental tuvieron oportunidad de adquirir la convicción de que el integracionismo no era solución para sus reivindicaciones sociales porque su portador, la burguesía criolla, no había sido capaz de concretar las aspiraciones libertarias por medio de la acción armada ante el temor de perder el liderazgo.

De aquellos que participaron a la cabeza del constitucional ismo de 1836 no todos tomaron el mismo camino político. Juan Kindelán, por ejemplo, pasó a integrar las filas del anexionismo; Muñoz del Monte se enroló en el reformismo vergonzante; Porfirio Valiente defendió en fecha temprana la necesidad de liberarse del yugo español sin compromisos con otra nación extranjera. En el oriente de Cuba, la generación que sucedió a los militantes de 1836 mostró la pasividad que les provocó el fracaso, pero la siguiente buscó la independencia a partir del 10 de octubre de 1836.

Habrían de transcurrir 32 años para que en el departamento Oriental se disiparan los temores a las insurrecciones negras. Entonces, los hacendados cubanos se hallaban en serias dificultades, muy comprometidos con sus refaccionistas peninsulares, y las diferencias de color se dejaban a un lado. Una buena parte de la burguesía cubana oriental percibió la existencia de una comunión de intereses entre todos los nacidos en estas tierras, lo que le llevó a concebir un programa de desarrollo precedido por la independencia. La lección había sido aprendida. 


\section{BIBLIOGRAFÍ}

-Bacardí y Moreau, Emilio (comp.), Cárdenas de Santiago de Cuba, $\mathrm{t}$. I, Tipografia Carbonell y Esteva, Barcelona, 1908.

-Cuadro estadístico de la siempre fiel isla de Cuba correspondiente al año de 1827, Oficina de la viuda de Arazoza y Soler, impresoras del Gobierno y Capitanía General por S. M., Habana, 1829.

- Cuadro estadístico de la siempre fiel isla de Cuba, correspondiente al año de 1846, Imprenta del Gobierno por S. M., Habana, 1847.

-Erenchun, Félix, Anales de la isla de Cuba. Diccionario administrativo, económico, estadístico y legislativo, Imp. La Antilla, Habana, 1858.

-Fernández de Castro, José Antonio, Medio siglo de historia colonial de Cuba. Cartas a José A. Saco ordenadas y comen. tadas (1823-1879), Ed. Ricardo Velosso, S. A., La Habana, 1923.

- García de Arboleya, José, Manual de la isla de Cuba, Imp. del Tiempo, Habana, 2da. ed., 1859.

-González Locertales, Vicente e Inés Roldánd e Montaud, "La minería del cobre en Cuba. Su organización, problemas administrativos y repercusiones sociales (18281849)", Revista de Indias, núms. 159-162, 1980, Madrid.
-Lorenzo, Manuel, Manifiesto del general don... a la nación española, Imp. por Campe, Cádiz, 1837.

- Memoria de la Sociedad Patrítica de La Habana, t. xx, Imp. del Gobierno y Capitanía General por S. M., Habana, 1839.

- Navarro García, Jesús Raúl, Entre esclavos y constituciones. (El colonialismo liberal de 1837 en Cuba), Escuela de Estudios Hispanoamericanos de Sevilla, Sevilla, 1991.

-Portell Vilá, Herminio, Historia de Cuba en sus relaciones con los Estados Unidos y España, t. I (1512-1853), Ed. Jesús Montero, La Habana, 1938.

-Representación documentada del muy ilustre Ayuntamiento de Santiago de Cuba y otras corporaciones a la reina nuestra señora, Imp. de la Real Sociedad Económica, Santiago de Cuba, 1835.

-Resumen del Censo de Población de la isla de Cuba a fines del año de 1841, Imp. del Gobierno por S. M., Habana, 1842.

-Resumen del Censo de Población de la isla de Cuba, Intendencia de Ejército y Hacienda, Habana, 1860.

- Villanova, Manuel, Economáa y civismo, Publicaciones del Ministerio de Educación, La Habana, 1945. 